\title{
Binding of zinc and calcium to inositol phosphates (phytate) in vitro
}

\author{
BY C. J.SIMPSON AND A. WISE* \\ Robert Gordon's Institute of Technology, Queen's Road, Aberdeen AB9 $2 P G$
}

(Received 2 November 1989 - Accepted 5 March 1990)

\begin{abstract}
Inositol compounds with three to five phosphate groups (IP3-IP5) were produced by hydrolysis of phytate (inositol hexaphosphate, IP6) and their binding affinities for calcium and zinc investigated at neutral pH with relative concentrations that had been found in a range of students' meals. Zn solubility was negligible at many of these concentrations, with less $\mathrm{Zn}$ bound to precipitates of $\mathrm{Ca}$-IP6 than Ca-IP5. The capacity to precipitate $\mathrm{Zn}$ at these ratios fell between IP5 and IP3. $\mathrm{Zn}$ was partially desorbed by soluble chelators (histidine and picolinate), especially when it had been adsorbed to preformed Ca-IP precipitates. A lower proportion of $\mathrm{Zn}$ was accessible to soluble chelators from Ca-IP4 than the other compounds. IP3-IP4 were hydrolysed by phytase more readily than IP5-IP6.
\end{abstract}

Zinc: Calcium: Inositol phosphates

Both in vitro and in vivo methods have proved valuable in furthering our understanding of the influence of phytate on zinc bioavailability in rats; from these experiments it has become clear that the calcium content of the diet is of vital importance (Wise, 1986). Binding studies have shown that trace amounts of $\mathrm{Zn}$ do not precipitate phytate in the absence of $\mathrm{Ca}$, but at concentrations present in typical rat diets, all $\mathrm{Zn}$ is bound to the $\mathrm{Ca}$-phytate precipitate in vitro. When fed on a variety of diets by Davies et al. (1985), rats gained weight in proportion to the molar ratio of $(\mathrm{Ca} \times$ phytate $): \mathrm{Zn}$. High bioavailability of $\mathrm{Zn}$ can be simply explained at low phytate, high $\mathrm{Ca}$ concentrations and at high phytate, low $\mathrm{Ca}$ concentrations; in the latter case, most of the phytate is not precipitated and is, therefore, hydrolysed by intestinal phytase (EC 3.1.3.26) (Bitar \& Reinhold, 1972). In rats fed on high-Ca diets, phytate hydrolysis appears to depend mainly on caecal bacterial phytase and this has been demonstrated by both in vivo (Wise \& Gilburt, $1982 a$; Wise et al. 1983) and in vitro techniques (Wise \& Gilburt, 1987). In vitro studies have also shown that various chelating agents like histidine are able to desorb some $\mathrm{Zn}$ from the $\mathrm{Zn}-\mathrm{Ca}-$ phytate precipitate, and the capacity of the rat's intestinal contents to desorb $\mathrm{Zn}$ has also been shown to depend on dietary protein (Wise \& Gilburt, 1982b). Similarly, in vivo studies have concluded that increased dietary protein is able to reduce the detrimental effect of dietary phytate on $\mathrm{Zn}$ absorption in rats and humans (Sandström et al. 1980; Davies, 1982).

The $\mathrm{Zn}$ available for desorption depends on the order in which $\mathrm{Zn}, \mathrm{Ca}$ and phytate are mixed; this may be important since when $\mathrm{Zn}$ is co-precipitated with $\mathrm{Ca}$ and phytate, a proportion appears to be located within the particles and hence is not readily desorbed (Wise \& Gilburt, 1983).

The classical ferric phytate precipitation method is usually interpreted in terms of inositol hexaphosphate (IP6), although other inositol phosphates (IPs) are also included in the precipitate (Anderson, 1963). Similarly, previous studies of the chemistry and biological 
effects of the IPs have generally employed IP6 (Wise, 1983). Although IP6 is the form synthesized by plants (Maga, 1982), this may be hydrolysed by heat in extrusion cooking (Sandberg et al. 1987), and enzymically either in the preparation of food (Nayini \& Markakis, 1983) or in the intestine as a result of exogenous (Sandberg et al. 1987), endogenous (Bitar \& Reinhold, 1972) or bacterial phytase (Wise \& Gilburt, 1987). In vivo experiments in quail (Coturnix coturnix) (Tao et al. 1986) and rats (Lönnerdal et al. 1989) have shown that inositol pentaphosphate (IP5) reduces $\mathrm{Zn}$ bioavailability in the same way as IP6 but lower IPs do not. The present study was designed to expand previous in vitro work on IP6 to its hydrolysis products, with particular emphasis on the amounts of $\mathrm{Zn}, \mathrm{Ca}$ and phytate present in human meals.

\section{METHODS}

Inositol tri-, tetra- and pentaphosphates (IP3, IP4 and IP5 respectively) were prepared from $20 \mathrm{~g}$ IP6 (Sigma Chemical Co., Poole, Dorset) at $\mathrm{pH} 4.0$ by autoclaving for either 30 or $60 \mathrm{~min}$ at $121^{\circ}$ and $103 \mathrm{kPa}$. After neutralization and dilution of the two hydrolysed samples, they were mixed and half was applied to a glass column $(35 \times 600 \mathrm{~mm})$ containing Dowex-1 ion-exchange resin of 200-400 mesh (Sigma Chemical Co.). It was eluted over a $0-0.95 \mathrm{M}$-hydrochloric acid linear gradient for $19.5 \mathrm{~h}$ and at $0.95 \mathrm{M}$ for $4.5 \mathrm{~h}$, at the rate of $200 \mathrm{ml} / \mathrm{h}$, and two hundred $25 \mathrm{ml}$ fractions collected (Phillippy et al. 1987). The separation was repeated to collect as much of the compounds as possible. They were identified by analysis of phosphate (Sumner, 1944) and inositol. The samples (2 ml) were sealed in Pyrex tubes containing $2 \mathrm{ml}$ concentrated $\mathrm{HCl}$, and hydrolysed at $110^{\circ}$ for $48 \mathrm{~h}$ (Fardiaz \& Markakis, 1981). They were then analysed by the sodium metaperiodate method of Agranoff et al. (1958). Inositol monophosphate (IP1) and diphosphate (IP2) eluted with phosphate but the other IPs were relatively well separated. Since different phosphate groups may be hydrolysed, pure compounds would not be expected to result from the reaction; different locations of phosphate groups may influence the elution characteristics. Samples closest to the molar ratios of IP3, IP4 and IP5 were neutralized and concentrated to $5 \mathrm{~mm}$ at $40^{\circ}$.

Ratios for the in vitro studies were chosen to cover the range found in meals consumed by nutrition students (Wise et al. 1987): IPs: $\mathrm{Zn}$ of 1, 5, 10, 15, 20, 30,40 and 80; Ca: $\mathrm{Zn}$ of $15,50,100,200,300$ and 500 . Duplicate portions of $5 \mathrm{ml} 0.125 \mathrm{~mm}$-zinc sulphate were mixed with calcium chloride and then IP added, the $\mathrm{pH}$ was adjusted to 7 , then made up to $25 \mathrm{ml}$ and centrifuged at $2400 \mathrm{~g}$ for $20 \mathrm{~min}$ to sediment the precipitate (Wise \& Gilburt, 1981). The proportion of metal remaining in solution was determined by atomic absorption spectrophotometry.

The effect of two chelating agents on desorption of $\mathrm{Zn}$ from IP3-IP6 was determined at $\mathrm{Ca}: \mathrm{Zn}$ and IP: $\mathrm{Zn}$ of 100 and 10 respectively. The molar ratios employed for picolinate: $\mathrm{Zn}$ and histidine: $\mathrm{Zn}$ were 50 and 250 respectively. The orders of addition were tested, and in each case five replicates were included in the experiment; the results were analysed by twoway analysis of variance. The proportion of co-precipitated $\mathrm{Zn}$ that was accessible to chelating agent was calculated from the following formula:

$$
\frac{100 b}{T} \times\left(1+\frac{T-c}{c}\right)
$$

where $b$ and $c$ are the amounts of $\mathrm{Zn}$ desorbed from the co-precipitated particles and the surface-bound particles respectively, and $T$ is the total amount of $\mathrm{Zn}$ originally added (Wise \& Gilburt, 1983). 
Five replicates containing $\mathrm{Ca}: \mathrm{Zn}: \mathrm{IP}$, as in the chelation experiments, were incubated with $3 \cdot 1 \mathrm{mg}$ wheat phytase (Sigma Chemical Co.) at $55^{\circ}$ and portions of $1 \mathrm{ml}$ removed after $0,0 \cdot 5,1,1 \cdot 5,2,3$ and $4 \mathrm{~h}$. The reaction was stopped by $2 \mathrm{ml}$ trichloroacetic acid $(125 \mathrm{~g} / \mathrm{l})$ and analysed for phosphate.

\section{RESULTS}

The solubilities of $\mathrm{Ca}$ and $\mathrm{Zn}$ in the presence of IPs at different ratios are shown in Fig. $1(a-f)$. At low Ca concentrations, there were clear differences, with less Ca precipitated and markedly less $\mathrm{Zn}$ bound to IP6 than IP5, particularly when more IP was present. At medium Ca concentrations, IP6 stood out as being the only compound that did not bind $\mathrm{Zn}$ well at high IP concentrations. The capacity to precipitate $\mathrm{Zn}$ fell between IP5 and IP3. Histidine and picolinate both desorbed $\mathrm{Zn}$ from IPs, to a greater extent when the $\mathrm{Zn}$ had been added to a preformed $\mathrm{Ca}$-IP precipitate (see Fig. 2). Histidine was relatively less effective than picolinate at the concentrations chosen only for IP6, but its effect was similar for the other IPs. The accessibility of $\mathrm{Zn}$ in co-precipitated $\mathrm{Ca}-\mathrm{IP}$ was similar whether estimated from the histidine or picolinate results (see Table 1). IP4 appeared to contain the greatest proportion of $\mathrm{Zn}$ within the particles, followed by IP5 and IP3, which were similar, and then IP6, which bore about $40 \%$ of the $\mathrm{Zn}$ near enough to the surface for desorption by the chelator. When picolinate was present before co-precipitation of $\mathrm{Zn}$ with $\mathrm{Ca}$ and IP could occur, the majority of the Zn remained in solution: IP6, 69\%; IP5, 69\%; IP4, 87\% ; and IP3, 99\%. These were similar values to the experiments in which $\mathrm{Zn}$ had been added after precipitation, and show that little $\mathrm{Zn}$ entered the particles. After incubation with phytase, more hydrolysis occurred with IP4 and IP3, compared with IP6 and IP5 (see Fig. 3).
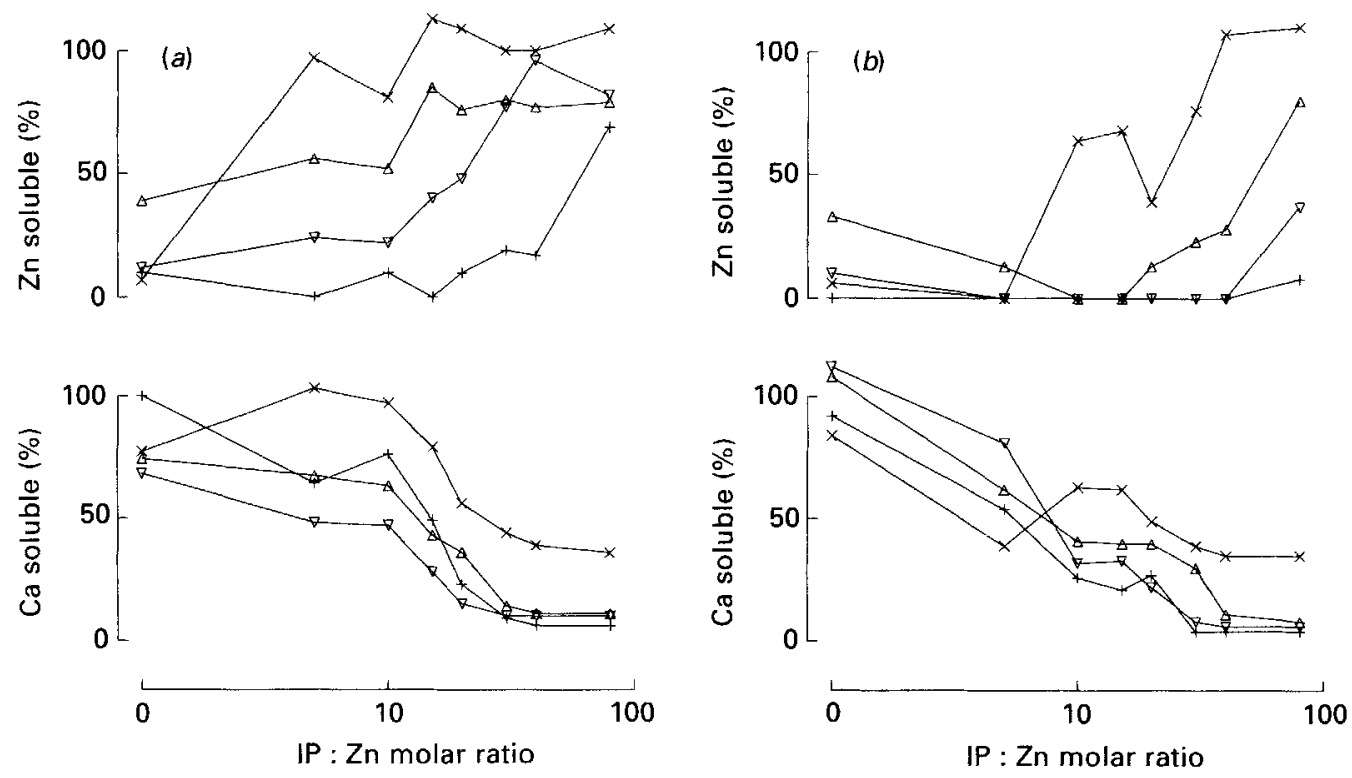

Fig. $1(a),(b)$. For legend see p. 228. 

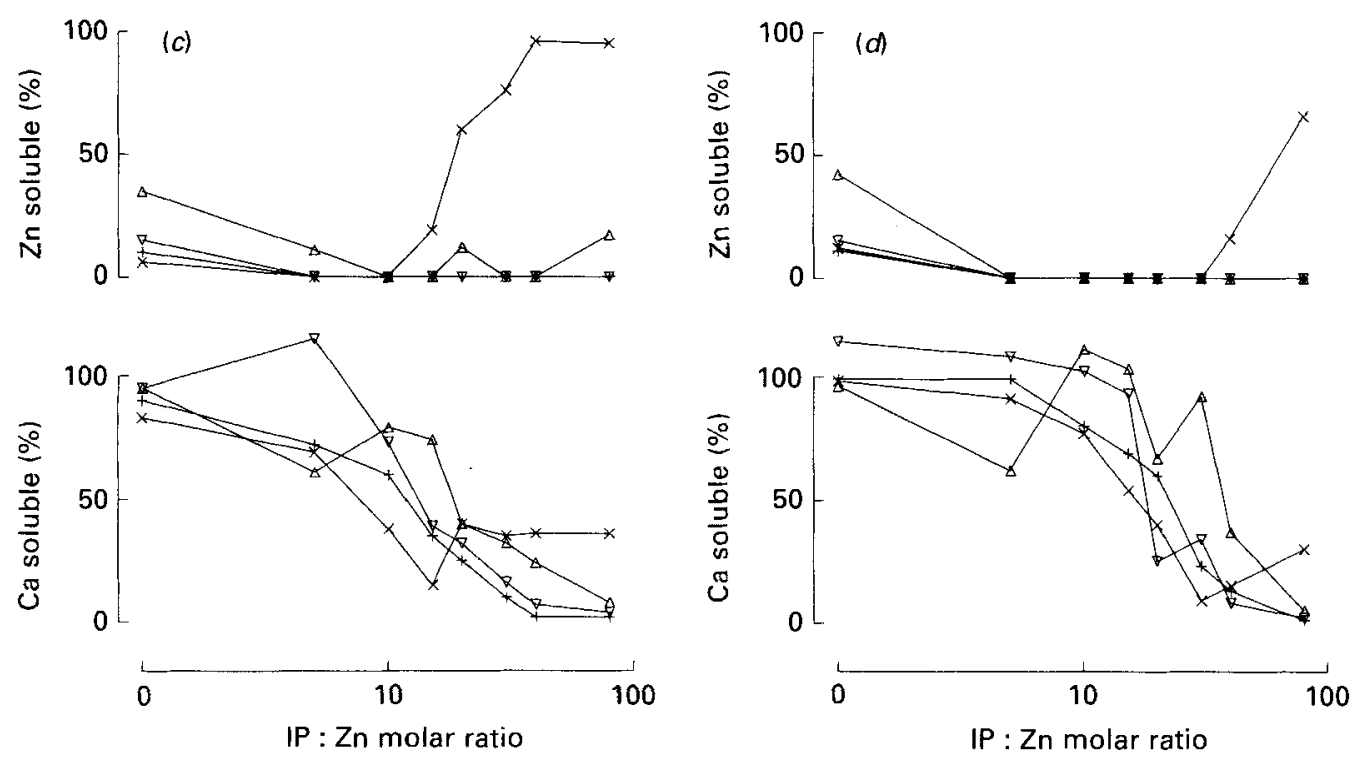

IP : Zn molar ratio
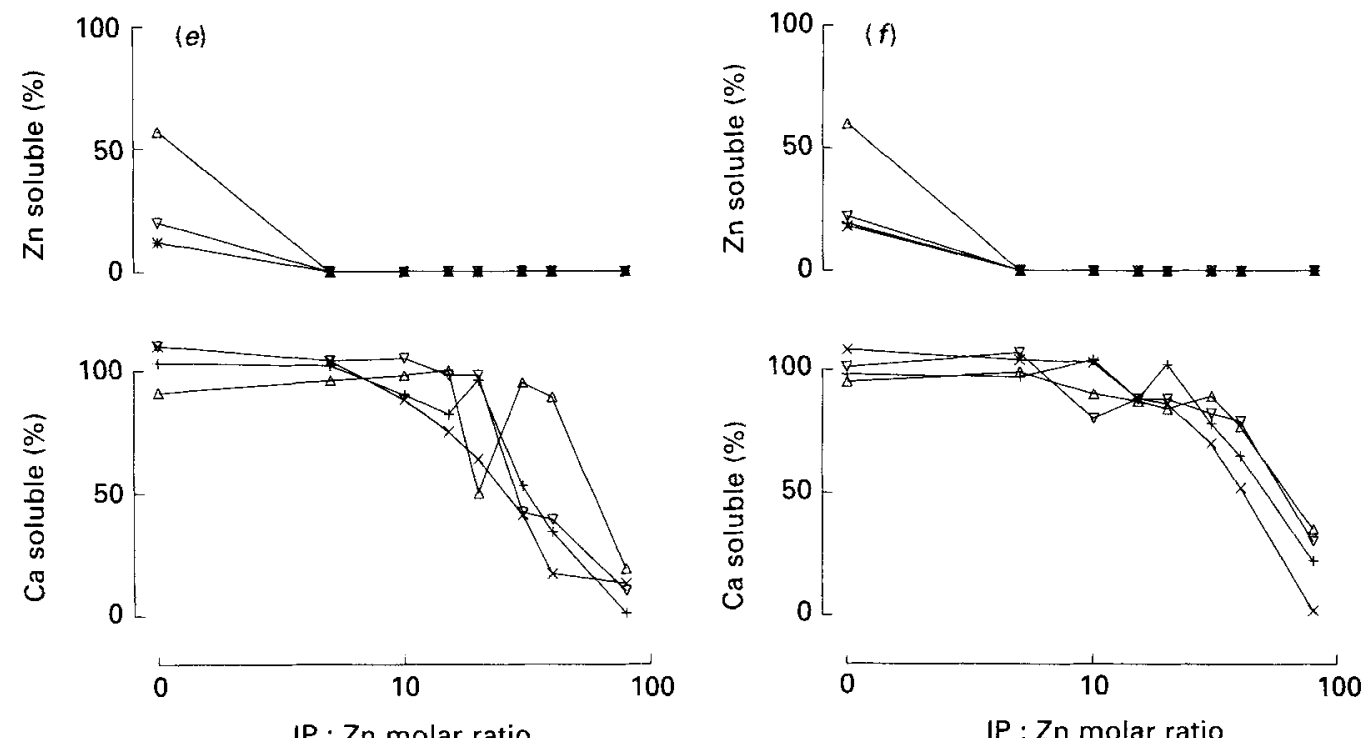

Fig. 1. Percentage of calcium and zinc in solution after precipitation of $\mathrm{Ca}, \mathrm{Zn}$ and inositol phosphates (IPs) at various molar ratios of $\mathrm{Ca}: \mathrm{Zn}$ and IP: $\mathrm{Zn}$. Ca: $\mathrm{Zn}$ ratios were $(a) 15,(b) 50,(c) 100,(d) 200,(e) 300,(f) 500$. Compounds are represented as follows: $(X)$ inositol hexaphosphate; $(+)$ inositol pentaphosphate; $(\nabla)$ inositol tetraphosphate; $(\triangle)$ inositol triphosphate. 


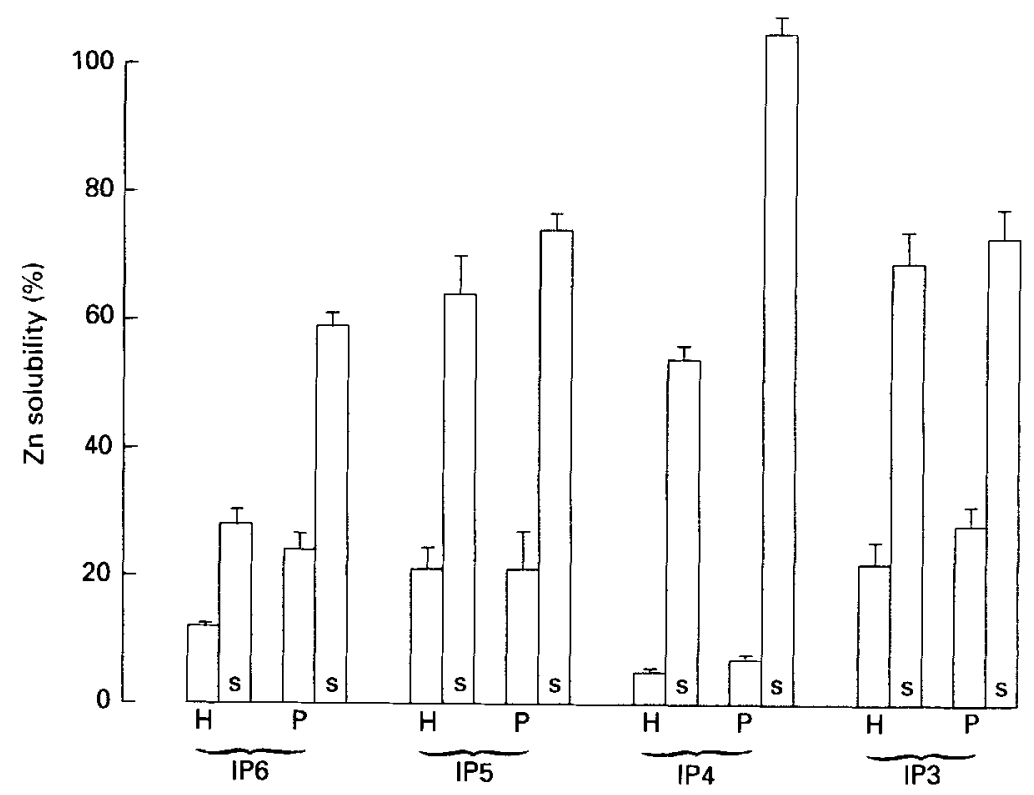

Fig. 2. Proportion of soluble zinc in the presence of histidine $(H)$ or picolinate $(P)$ when $\mathrm{Zn}$ had either a surface location (s) or had been co-precipitated with calcium and inositol phosphates (IPs) at molar ratios of 100:1:10 (Ca:Zn:IP), 250:1 (histidine: Zn) and 50:1 (picolinate:Zn). IP6, IP5, IP4 and IP3 are inositol hexa-, penta-, tetraand triphosphates respectively. Values are means with their standard deviations represented by vertical bars.

Table 1. Accessibility (\%) of chelating agents to zinc after it had been co-precipitated with calcium and inositol phosphate (IP) at molar (Ca: $\mathrm{Zn}: I P$ ) ratios of $100: 1: 10$; the remainder of the $\mathrm{Zn}$ being assumed to be located within the particles

\begin{tabular}{lllllll} 
& Chelating agent & & IP6 & IP5 & IP4 & IP3 \\
& Histidine & 42 & 33 & 10 & 32 \\
& Picolinate & 43 & 28 & 7 & 38 \\
\hline
\end{tabular}

IP6, IP5, IP4, IP3, inositol hexa-, penta-, tetra- and triphosphates respectively

\section{DISCUSSION}

Clearly it is now considered insufficient to perform studies exclusively with the IP6 form of phytate, and it has been recognized that further research is needed on IPs with fewer phosphate groups (Mills \& Davies, 1988). The proportions of the IPs in a bran-flake cereal were found to be 7,13,32 and 44\% of the total as IP3-IP6 respectively; somewhat higher percentages as IP6 were found in canned kidney beans (Phaseolus vulgaris) and white bread (Phillippy et al. 1988). It is hoped that future food analysis will give more information on which to base an estimate of the dietary content of all the IPs, but at present no such attempt appears to have been made. The speciation in the small intestine should deserve greater attention in future studies. For example, Sandberg et al. (1987) has shown the following percentages of IP3-IP6 after feeding bran, which itself contained mainly IP6: 18, 23,14 and 45 .

It appeared that IP5 had the strongest binding capacity for $\mathrm{Zn}$, especially at low $\mathrm{Ca}$ concentrations, while IP6 had the weakest. Between IP5 and IP3 there was a decline in binding activity so that solubilities were generally greatest for IP3, as might be expected 


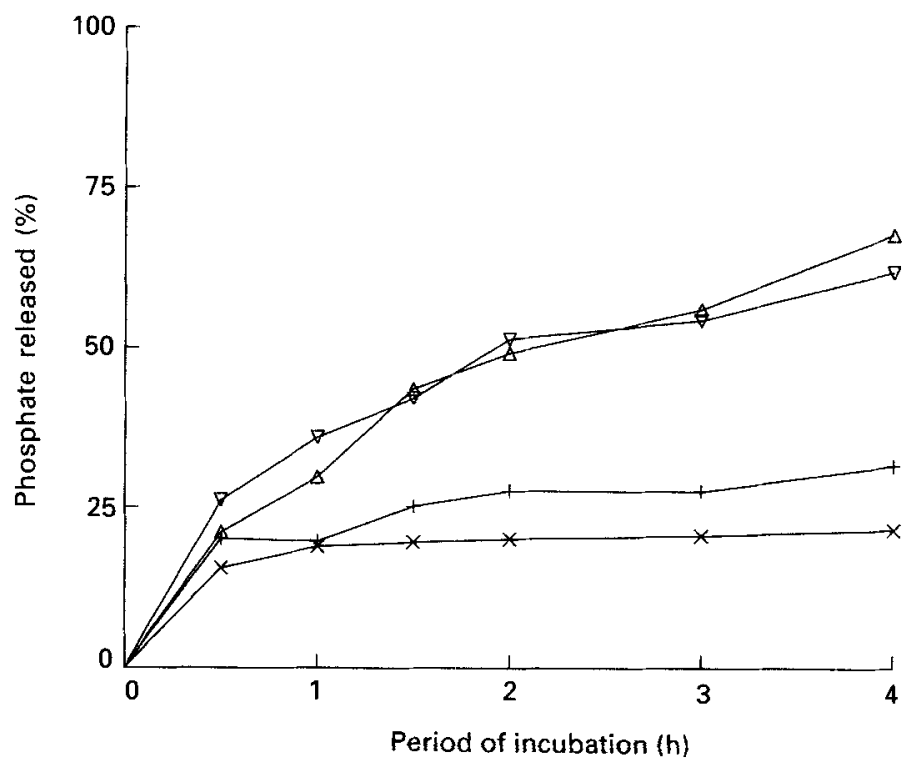

Fig. 3. Percentage of phosphate released from calcium-zinc-inositol phosphates (molar ratio 100:1:10) by phytase (EC 3.1.3.26) after different time intervals. Compounds are represented as follows: (X), inositol hexaphosphate; $(+)$, inositol pentaphosphate; $(\nabla)$, inositol tetraphosphate; $(\triangle)$, inositol triphosphate.

from the number of phosphate groups. It is difficult to compare these results directly with others in the literature, because the conditions of precipitation are rarely comparable. It is known that Ca-IP6 forms an amorphous precipitate (Hoff-Jørgensen, 1944), and that generally the particle size increases as the ratio of Ca: IP6 increases (Campbell et al. 1981). It has also been shown that precipitation of Ca-IP6 may be reduced at low Ca:IP6 ratios by sodium chloride (Wise, 1983) and milk (Clydesdale, 1988), and it may also bind to protein (De Rham \& Jost, 1979) and peptides (Cheryan, 1980). The relatively low binding of $\mathrm{Zn}$ to IP6 under certain conditions found here is not surprising, since it has been shown previously that half the $\mathrm{Zn}$ was soluble at $\mathrm{Ca}: \mathrm{IP} 6: \mathrm{Zn}$ molar ratios of $6: 3: 1$ (Clydesdale, 1988). Further work is needed to investigate the effect of a wide range of substances on the binding of $\mathrm{Zn}$ to the other IPs under simulated intestinal conditions, but it can be suggested from these in vitro studies that most of the $\mathrm{Zn}$ would be bound to IPs at concentrations found in practical meals.

Differences in the structures of Ca-IP complexes precipitated in the present study have been inferred from their reactions with chelators, IP6 having differential competitive activity against histidine and picolinate at the concentrations tested, for both coprecipitated and surface-bound precipitates. Only a few amino acids previously tested (Wise \& Gilburt, 1982b) were able to compete with Ca-IP6, of which histidine was a particularly potent example. Further work is required to show whether this differential competitiveness imparts a particular advantage to IP6 as a $\mathrm{Zn}$-binding agent in the intestine. Stability constants have been used to predict the potential effects on growth of such compounds (Clydesdale, 1988); those with low constants may be unable to compete with phytate, and those with excessively high constants may desorb $\mathrm{Zn}$, but fail to yield the metal to body tissues.

In vitro experiments are unable to mimic all the conditions in vivo, and in this case the order of reaction appears to be of great importance. There is no reason to suppose that 
dietary $\mathrm{Zn}$ is added to the mixture after precipitation, but this may the case for endogenously secreted $\mathrm{Zn}$. In a rat model, endogenous $\mathrm{Zn}$ has also been shown to bind to IP6, as demonstrated by its lower re-absorption (Davies \& Nightingale, 1975), but it is possible that a surface location would confer some advantage for endogenous $\mathrm{Zn}$. It is also possible that the presence of some chelators before precipitation might reduce the incorporation of some $\mathrm{Zn}$ into the particles, as demonstrated in these in vitro experiments with picolinate.

The formula used to calculate the proportion of $\mathrm{Zn}$ accessible to the chelating agent has been derived from an assumption that the partition between the soluble chelator and precipitate is the same for a co-precipitated complex as it is for one in which $\mathrm{Zn}$ was added after precipitation. The concept of accessibility is important, but difficult to validate in vivo. It has previously been shown that low Zn:IP6 ratios lead to higher accessibilities to a soluble chelator than do high ratios, and this would theoretically be beneficial in highphytate diets (Wise, 1983). It appeared that $\mathrm{Zn}$, co-precipitated with IP4, would most likely be incorporated into the particles, and this might be expected to lead to a larger effect of this compound on $\mathrm{Zn}$ availability. However, experiments in which the individual compounds were fed to quail (Tao et al. 1986) and rats (Lönnerdal et al. 1989) showed that IP6 and IP5 reduced Zn bioavailability whereas IP4 and IP3 did not. It is possible that the present results employing phytase might contribute to an understanding of this phenomenon. Both these compounds were most easily hydrolysed by phytase, even though they were present in particulate form. Presumably they are more soluble and, hence, present themselves in greater concentrations to the enzyme. Further work is required to establish the extent of phytate hydrolysis in humans; hydrolysis of soluble sodium-IP6 is not a good model for phytase activity in vivo where $\mathrm{Ca}$ is present, and $\mathrm{Ca}-\mathrm{IP} 6$ is less easily hydrolysed than other $\mathrm{Ca}-\mathrm{IPs}$ and may, therefore, give a false impression of the overall phytase activity. Assaying phytase activity may be further complicated by the fact that phytase is activated by $\mathrm{Zn}$ (Bitar \& Reinhold, 1972), which may explain how phytate reduces the mucosal activity of phytase (Bhandari, 1980).

The authors would like to thank the Rowett Research Institute and many of its staff for help in conducting this study.

\section{REFERENCES}

Agranoff, B. W., Bradley, R. M. \& Brady, R. O. (1958). The enzymatic synthesis of inositol phosphates. Journal of Biological Chemistry 233, 1077-1083.

Anderson, G. (1963). Effect of iron/phosphorous ratio and acid concentration on the precipitation of ferric inositol hexaphosphate. Journal of the Science of Food and Agriculture 14, 352-359.

Bhandari, S. D. (1980). Effect of phytate feeding with and without protein and vitamin D deficiencies on intestinal phytase activity in the rat. Indian Journal of Biochemistry and Biophysics 17, 309-312.

Bitar, K. \& Reinhold, J. G. (1972). Phytase and alkaline phosphatase activities in intestinal mucosae of rat, chicken, calf, and man. Biochemica et Biophysica Acta 268, 442-452.

Campbell, J., Bellen, J. C., Baker, R. J. \& Cook, D. J. (1981). Technetium-99m calcium phytate - optimization of calcium content for liver and spleen scintigraphy. Journal of Nuclear Medicine 22, 157-160.

Cheryan, M. (1980). Phytic acid interactions in food systems. CRC Critical Reviews in Food Science and Nutrition 13, 297-335.

Clydesdale, F. M. (1988). Mineral interactions in foods. In Nutrient Interactions, pp. 73-113 [C. E. Bodwell and J. W. Erdman, editors]. New York: Marcel Dekker Inc.

Davies, N. T. (1982). Effects of phytic acid on mineral availability. In Dietary Fiber in Health and Disease, pp. 105-116 [G. V. Vahouny and D. Kritchevsky, editors]. New York: Plenum Press.

Davies, N. T., Carswell, A. J. P. \& Mills, C. F. (1985). The effect of variation in dietary calcium intake oni the phytate-zinc interaction in rats. In Trace Elements in Man and Animals-TEMA 5, pp. $456-457$ [C. F. Mills, I. Bremner and J. K. Chesters, editors]. Slough: Commonwealth Agricultural Bureaux.

Davies, N. T. \& Nightingale, R. (1975). The effects of phytate on intestinal absorption and secretion of zinc, and whole-body retention of $\mathrm{Zn}$, copper, iron and manganese in rats. British Journal of Nutrition 34, 243-258. 
De Rham, O. \& Jost, T. (1979). Phytate-protein interactions in soybean extracts and low-phytate soy protein products. Journal of Food Science 44, 596-600.

Fardiaz, D. \& Markakis, P. (1981). Degradation of phytic acid in oncom (fermented peanut press cake). Journal of Food Science 46, 523-525.

Hoff-Jørgensen, E. (1944). Investigations of the solubility of calcium phytate. Kongelige Danske Videnskabernes Selskabs Matematiske-Fysiske Meddelelser 21, 1-27.

Lönnerdal, B., Sandberg, A. S., Sandström, B. \& Kunz, C. (1989). Inhibitory effects of phytic acid and other inositol phosphates on zinc and calcium absorption in suckling rats. Journal of Nutrition 119, $211-214$.

Maga, J. A. (1982). Phytate: its chemistry, occurrence, food interactions, nutritional significance, and methods of analysis. Journal of Agriculture and Food Chemistry 30, 1-9.

Mills, C. F. \& Davies, N. T. (1988). Report of a study group on the significance of dietary phytate, its analogues and other dietary factors on trace element availability in man. Nutrition Abstracts and Reviews A58, 501-516.

Nayini, N. R. \& Markakis, P. (1983). Effect of fermentation time on the inositol phosphates of bread. Journal of Food Science 48, 262-263.

Phillippy, B. Q., White, K. D., Johnston, M. R., Tao, S. H. \& Fox, M. R. S. (1987). Preparation of inositol phosphates from sodium phytate by enzymic and non-enzymic hydrolysis. Analytical Biochemistry 162, $115-121$.

Phillippy, B. Q., Johnston, M. R., Tao, S. H. \& Fox, M. R. S. (1988). Inositol phosphates in processed foods. Journal of Food Science 53, 496-499.

Sandberg, A. S., Andersson, H., Carlsson, N. G. \& Sandstrom, B. (1987). Degradation products of bran phytate formed during digestion in the human small intestine: effect of extrusion cooking on digestibility. Journal of Nutrition 117, 20612065.

Sandström, B., Arvidsson, B., Cederblad, A. \& Bjorn-Rasmussen, E. (1980). Zinc absorption from composite meals. The significance of wheat extraction rate, zinc, calcium, and protein content in meals based on bread. American Joumal of Clinical Nutrition 33, 739-745.

Sumner, J. B. (1944). A method for the colorimetric determination of phosphorus. Science 100, 413414.

Tao, S. H., Fox, M. R. S., Phillippy, B. Q., Fry, B. E., Johnston, M. L. \& Johnston, M. R. (1986). Effect of inositol phosphates on mineral utilization. Federation of American Societies of Experimental Biology $45,819$.

Wise, A. (1983). Dietary factors determining the biological activities of phytate. Nutrition Abstracts and Reviews A53, 791-806.

Wise, A. (1986). Influence of calcium on trace metal-phytate interactions. In Phytic Acid-Chemistry \& Applications, pp. 151-160 [E. Graf, editor]. Minneapolis: Pilatus Press.

Wise, A. \& Gilburt, D. J. (1981). Binding of cadmium and lead to the calcium-phytate complex in vitro. Toxicology Letters $9,45-50$.

Wise, A. \& Gilburt, D. J. (1982a). Phytate hydrolysis by germfree and conventional rats. Applied and Environmental Microbiology 43, 753-756.

Wise, A. \& Gilburt, D. J. (1982b). In vitro competition between calcium phytate and the soluble fraction of rat small intestine contents for cadmium, copper and zinc. Toxicology Letters 11, $49 \ldots 54$.

Wise, A. \& Gilburt, D. J. (1983). Accessibility of trace metals, co-precipitated with calcium phytate, to soluble chelating agents. Nutrition Research 3, 321-324.

Wise, A. \& Gilburt, D. J. (1987). Caecal microbial phytate hydrolysis in the rat. Human Nutrition: Food Science and Nutrition 41F, 47-54.

Wise, A., Lockie, G. M. \& Liddell, J. (1987). Dietary intakes of phytate and its meal distribution pattern amongst staff and students in an institution of higher education. British Journal of Nutrition 58, 337-346.

Wise, A., Richards, C. P. \& Trimble, M. L. (1983). Phytate hydrolysis in the gastrointestinal tract of the rat followed by phosphorus-31 Fourier transform nuclear magnetic resonance spectroscopy. Applied and Environmental Microbiology 45, 313-314. 